Revista de la red interuniversitaria de estudios sobre las literaturas rioplatenses contemporáneas en Francia

$9 \mid 2013$

Homenaje a Ana María Barrenechea

\title{
Rueda de mujeres. Acerca de Susana Thénon
}

\section{Paola Cortés Rocca}

URL: http://journals.openedition.org/lirico/1125

DOI: 10.4000/lirico.1125

ISSN: 2262-8339

Editor

Réseau interuniversitaire d'étude des littératures contemporaines du Río de la Plata

\section{Referencia electrónica}

Paola Cortés Rocca, «Rueda de mujeres. Acerca de Susana Thénon », Cuadernos LIRICO [En línea],

9 | 2013, Puesto en línea el 01 septiembre 2013, consultado el 30 abril 2019. URL : http:// journals.openedition.org/lirico/1125; DOI : 10.4000/lirico.1125

Este documento fue generado automáticamente el 30 abril 2019.

\section{(c) (i) (9)}

Cuadernos LIRICO está distribuido bajo una Licencia Creative Commons Atribución-NoComercialSinDerivar 4.0 Internacional. 


\title{
Rueda de mujeres. Acerca de Susana Thénon
}

\author{
Paola Cortés Rocca
}

Empezar a decir versos es entrar en una danza

verbal

Paul Valéry

\section{Minúsculas distancias}

1 En 1984, Susana Thénon publica distancias, un libro que reúne 39 poemas en los que había comenzado a trabajar en la década del 60. El poemario se abre con el agradecimiento “a quienes apuntalaron la construcción de este libro": Ana María Barrenechea, Renata Treitel e Iris Scaccheri. La poeta agradece, en orden, a la crítica, a la traductora y a la bailarina. Se trata de un grupo de mujeres con el que mantiene lazos profesionales pero también afectivos, relaciones de amistad y convivencia. Pero también se trata de mujeres que encarnan una serie de disciplinas con las que la poesía de Thénon entabla un diálogo sostenido y provechoso. De hecho, más que vínculos y contactos más o menos fluidos con esos discursos, podría decirse que, por ejemplo, la reflexión de la crítica literaria y los problemas que hacen a la práctica y a la especulación teórica sobre la traducción son los materiales mismos con los que trabaja el lenguaje poético de Thénon. Así, los agradecimientos señalan deudas y dones : de la crítica viene el "aliento", la legitimación o la verificación del valor estético de la obra, pero también el aire, el soplo y todo aquello que vivifica la obra y la pone a andar; de la traducción, viene, en cambio, la persistencia en el trabajo con la palabra, el tesón, la disciplina, el método. Lo que "infunde"- el verbo también es de Thénon - la danza es "la visión definitiva para reelaborar y completar esta obra, cuya duración lindaba peligrosamente con lo interminable” (Thénon 1984 : 6). Como ocurre con la traducción, algo del orden de la disciplina viene del universo de la danza, algo que detiene el vagabundeo del lenguaje, la compulsión a la reescritura infinita. La danza le otorga cierre a la poesía ; la danza le infunde una visión que hace posible la completitud. 
2 En el "Epílogo" que cierra distancias, Ana María Barrenechea califica a este libro -y al trabajo de Thénon en general-como una "experiencia textual única por la complejidad de relaciones simultáneas que establece en todas las direcciones y todos los niveles" (Barrenechea 1984: 85). El texto crítico recorre las operaciones de un lenguaje que "fragmenta, quiebra y desgarra, y a la vez organiza una constelación poética" (ídem), un lenguaje cuya "extrañeza no impide la comunicación. Todo lo contrario. Lo que hace es pedirla, incitarla. El libro con la variedad de voces que en él dialogan, dice al lector, sin descanso : busca, soy múltiple, no te detengas, no te conformes" (ídem).

3 Y efectivamente, no sólo el poemario trabaja con el juego entre distancias y cercanías, intercambios y fronteras entre lenguajes y disciplinas, es la práctica misma que Thénon lleva adelante, la que también llama al movimiento y la multiplicidad. El texto de Barrenechea comienza evocando una carta en la que Susana Thénon "me comunicaba" dice la crítica -, el comienzo de este proyecto que culminaría en la publicación de distancias y le enviaba dos de los poemas que consideraba terminados. La poeta escribe y le envía dos de esas "distancias" a su amiga. Seguramente ella las comenta y finalmente, cuando se organiza la publicación, escribe el "Epílogo", uno de los tantos textos en los que Barrenechea trabajará sobre la obra de Thénon. ${ }^{1}$ Ana María Barrenechea está en el comienzo de la obra de Thénon -recibe los primeros poemas- y en el epílogo que la cierra, con un texto que, ubicado al final del libro, relee, es decir, vuelve a abrir el poemario.

4 Esta circularidad dada por el envío de cartas y lecturas que anticipan y cierran la obra está en la organización misma del libro. El texto crítico revisa el poemario pero es éste mismo el que, al final, propone volver a empezar: el primer poema de distancias y el último son el mismo poema. La estructura circular es, además, material temático de ese poema de apertura y cierre :

la rueda se ha detenido se ha deteni-

dos tres dos tres dos la rueda (Thénon $1984: 9$ y 83)

5 La primera y última "distancia" nombra una rueda que se detiene. La primera vez, es decir, en el primer poema, se detiene para dar paso a todo el poemario; la segunda, es decir, en el mismo poema pero ahora al final del libro, lo hace como si nos dijese, la rueda fue ese movimiento del lenguaje que produjo todos estos poemas. Ahora sí va a detenerse, con este último sí se detiene la ronda de la poesía. Pero nosotros sabemos que no es así, luego viene el epílogo que, ahora con la lengua y el vocabulario de la crítica, repasa la poesía de Thénon y evoca incluso un pasado pretextual, ese momento anterior a la existencia del libro, cuando Ana María Barrenechea recibe dos poemas por carta.

6 Ese ser múltiple al que se refiere el "Epílogo" se construye a partir de "un lenguaje contradictorio" que "lee y traduce un mundo contradictorio, con opuestos simultáneos" o con "procesos de metamorfosis" y “autometamorfosis", propone Barrenechea (1984 : 87). La voz poética explora y construye un Yo que inscribe en sí la alteridad y el devenir -"soy dos / una igual una / sin siempre" sentencia la distancia 17. Transformación y otredad se dan también en el juego de esa rueda que, ya en su detención -falsa o momentánea -, tiene inscripta la alteridad del "dos" - que debería cerrar el verso anterior ("deteni-“) pero en realidad abre un verso nuevo. Ese movimiento que se detiene para seguir o que termina para volver a empezar, ese juego de la rueda o la rueda como juego, cuenta presupone, narra, contabiliza-con dos o con tres. La rueda no funciona sola, requiere de dos o tres que la pongan en funcionamiento para incorporar, como parte del juego, el relato sobre lo que se pone a circular, sobre lo que -como dice el mismo poema - "arrojara 
sus migas", sobre lo que se desgrana entre amigas. El poema de la rueda ocupa un lugar privilegiado en el libro y produce esta estructura circular que sintetiza la práctica estética de Thénon. Se trata de una poética que cuenta (con) la circulación lúdica de dones y préstamos, correspondencias, lecturas y comentarios, agradecimientos y deudas entre una serie de disciplinas y lenguajes $\mathrm{y}$, también, entre una rueda de mujeres que le ponen el cuerpo -y el nombre - a esas prácticas : Susana, Renata, Iris, Ana y vuelta a empezar.

Esa interdisciplinariedad surge de una relación vital con esos lenguajes que obviamente no existen en un espacio ideal o teórico y que tampoco se piensan como prácticas reales pero más o menos autónomas o profesionales. La relación con la crítica y la traducción se trama en una serie de correspondencias, de intercambios materiales concretos, porque los lenguajes no viven en algún lugar ancho y ajeno o paralelo al de la vida cotidiana, sino que están encarnados en esta serie de sujetos reales y concretos unidos por una corriente de afectos. La práctica poética de Thénon -y lo mismo podría decirse de la producción de Barrenechea, Treitel y Scaccheri- enlaza gente, discursos y saberes. Es por eso que este libro -pero también cualquier libro, cualquier poema de Thénon - no es un objeto cerrado sobre sí mismo, que existe en la pureza de su completitud e invita a la contemplación, sino un punto dentro de una tejido, una parada en el movimiento de la rueda, que en su andar interminable ahonda vínculos existentes e inventa otros nuevos.

\section{Libro marcado}

En un ejemplar de distancias, Barrenechea escribe en lápiz una serie de notas : consigna las distintas versiones y borradores que existen de cada poema, hace comentarios también vinculados al sentido de algunos términos, a los modos en que se enlazan con otros del mismo poema o de otros. Por ejemplo: "Hay un borrador en lápiz sin tachaduras", anota Barrenechea junto al tercer poema del libro (Thénon 1984: 11). ${ }^{2} \mathrm{La}$ crítica genética trabaja con el desarrollo de los textos, con los distintos "pre-textos" o variantes que incluyen manuscritos, borradores, ediciones con correcciones del autor, con el fin de dar cuenta de un proceso, más que de un producto final y terminado. ${ }^{3}$ Piensa entonces en los distintos momentos que implica la escritura, analiza sus transformaciones y conjetura explicaciones para esos cambios. Por ejemplo, junto al poema 6, Barrenechea consigna las diferentes versiones del texto (17):

1) en una hoja chica : poema V 10-III-68

2) Etapa interm.

3) En copia de Renata (28-febrero-1993)

Sólo hace esta corrección v. 7 "llueve sombra avergonzada

4) $\mathrm{LIBRO}^{4}$

9 La poesía no es sólo la que se imprime en el libro -ni es éste su estado definitivo o privilegiado, tal como la crítica genética sugeriría con su revalorización de las versiones pre-textuales -; ella circula en cartas y listas; se anticipa, se reproduce, se copia y se corrige. En las notas que Barrenechea deja en este ejemplar del libro de Susana Thénon puede leerse, además de aquello que puede interesar al estudioso de la genética textual versiones de los poemas de Thénon pero también, los "pre-textos" del trabajo crítico de Barrenechea sobre Thénon -, los rastros de un modo particular de circulación de la palabra. 


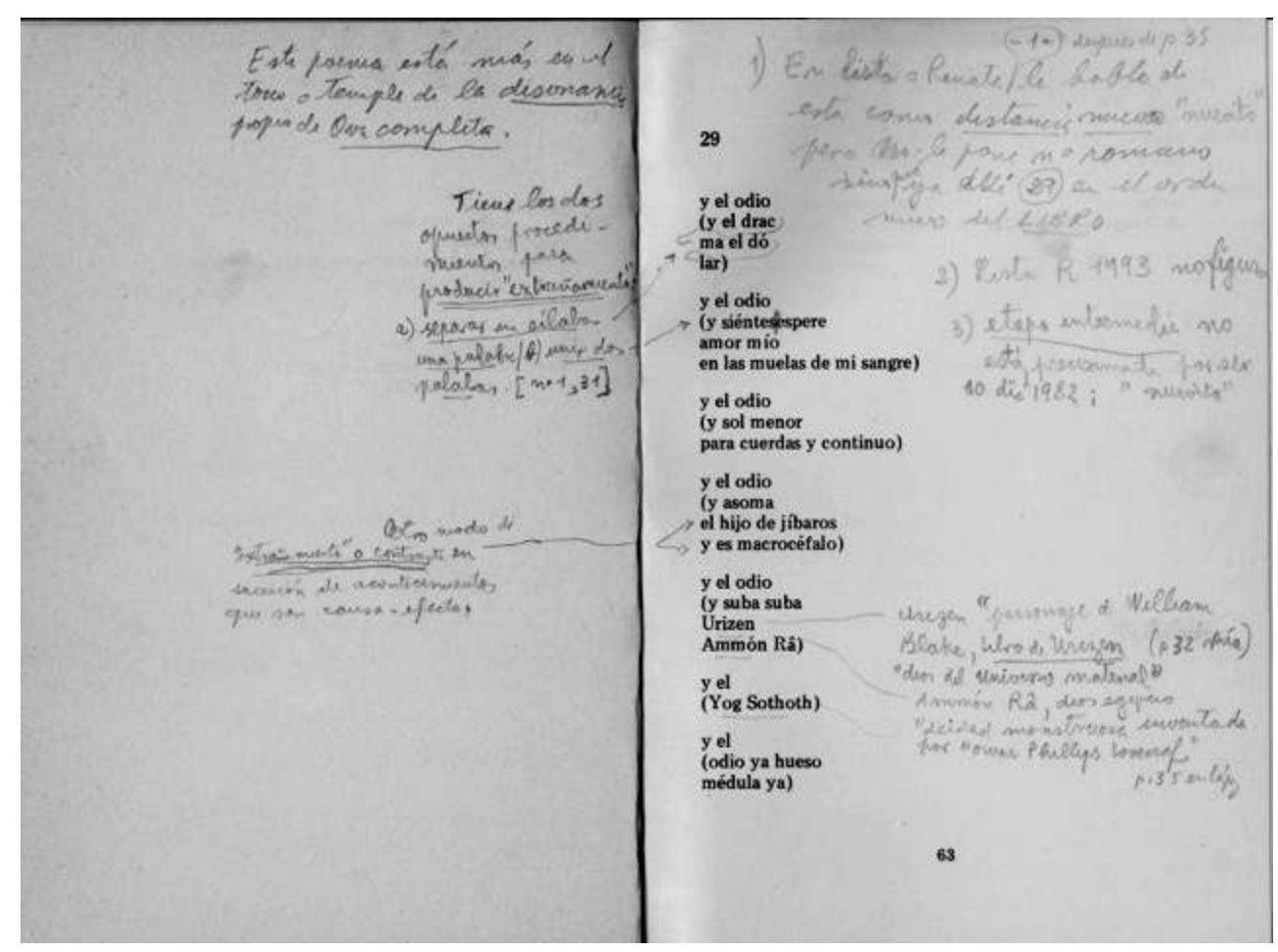

Figura 1: Página de distancias con anotaciones de Ana María Barrenechea menos última, del poemario de Thénon, objeto serializado y repetido-se vuelve ahora pieza única, borrador de un posible artículo de Barrenechea, cuaderno de notas, manuscrito de una voz crítica que vuelve a abrir el circuito de la palabra. $Y$ es que no hay sino versiones y más versiones de la escritura poética y crítica, de lo que se dice en una lengua y en otra, de lo que se escribe, se traduce, se lee, interpreta y reescribe. El circuito de la palabra fluye y se espesa en borradores en lápiz, copias y variantes que producen la ilusión o la certeza de que hay tantas versiones posibles -del poema, de su traducción, de su comentario crítico-como participantes, lectoras o destinatarias de la ronda. Así, en la página que tiene impreso el poema 10 , Barrenechea aclara que éste es el " $\mathrm{n}^{\circ} \mathrm{VI}$ en carta a Renata (igual al libro) que ella me mandó copiada 28 feb. 93 junto con otros poemas" (Thénon 1984 : 25). Sobre y al costado del poema 11, anota Barrenechea : "Parece que es la última versión entregada a Renata en diciembre de 1982"; e inmediatamente aclara: “Tengo una anotac. mía con variantes" (27). La versión de ella y la mía, la de la traductora y la de la crítica: hace tiempo que la palabra dejó de pertenecerle a los poetas, hace tiempo que dejó de ser letra petrificada en el libro. Ahora más que nunca es un objeto que circula y muta, que se posee pero también se comparte : "Tengo entre papeles sueltos el poema este copiado a máquina” es la anotación que corresponde al poema 28 (61). 
12 Al rastrear, comparar e interpretar borradores y manuscritos, al regresar sobre aquello que se consideraba desechable y provisorio frente a la fijeza y lo definitivo del libro, la crítica genética recupera el protagonismo del acto y el proceso de la escritura, largamente opacado por el objeto, el resultado, el producto de ese proceso. Al mismo tiempo, en ese gesto, pareciera reponer cierta dimensión aurática perdida para la escritura, desde hace siglos, con la reproducción mecánica de la palabra. Hay algo de eso en aquellas frases que describen, con extraordinario detalle, la materialidad de las versiones : "copiado a mano en una hojita sin número", "en las mismas hojas que usa Susana", "en el reverso, con tinta azul" ( 65,25 y 11). Si bien ese detenerse en la minucia que linda con el fetichismo puede evocar esa mirada de absoluto respeto con la que el crítico contempla los papeles perdidos y más o menos inaccesibles del autor, también puede leerse aquí como una muestra más de la cercanía y el cariño que se tiene con aquellos objetos que quedan como indicios de una amiga con la que la poesía y la crítica se integraba a la rueda de la conversación interminable. Es cierto que la escritura recupera cierto rasgo aurático, a través de estas anotaciones que giran alrededor del aquí y ahora de los "originales" estatuto que adquieren las hojitas copiadas a mano y por lo tanto irrepetibles, mencionadas por las anotaciones de Barrenechea. Pero también es cierto que esos originales proliferan tanto que expían su dimensión religiosa y museística. Son únicos y son irrepetibles, pero reconducen una y otra vez a la dimensión de acto de las prácticas escriturarias. Son únicos e irrepetibles del mismo modo que lo es cada instante, cada gesto, cada charla, cada comentario que se comparte con un otro que, como la poesía misma de Thénon lo afirma una y otra vez, nunca es igual a sí mismo. Se trata entonces de múltiples y cambiantes dimensiones auráticas de la palabra, hecha no sólo de trazos y huellas - que no desdeñan las zonas más o menos marginales de lo escriturario como las cartas y listas ${ }^{-6}$, sino también de dichos y comentarios.

13 Si la tradición de la crítica genética compara papeles y notas, Barrenechea agrega además la dimensión de la voz, que se anexa y se homologa con la escritura -o al menos, adquiere un valor similar. El verso 12 del primer poema termina con la palabra "mar", que está un poco más lejos de las anteriores. Barrenechea la envuelve en un círculo y con una línea la une a una anotación en lápiz: "S. dice "la palabra debe estar sola"' $(9$, el destacado es mío). En este caso, la voz de Thénon vuelve al presente a través del registro de la crítica. Vuelve para reinar sobre el diseño de la página, para confirmar que el uso del blanco es otro de los procedimientos de producción de sentido en la poesía. En otros casos, el decir de la poeta encauza el caudal semántico y reorienta las interpretaciones posibles. En este mismo poema, Barrenechea ha subrayado la palabra "sola" del octavo verso ("que arda sola eterna") y al costado indica “"es una mujer' dice S." (9). La letra manuscrita de Thénon o las versiones de los poemas mecanografiados tienen una existencia material concreta ; la voz de Susana Thénon también adquiere esa existencia material, ese eterno presente -esa eterna presencia -, a través de la memoria de Barrenechea y de sus anotaciones.

Esa voz que se recupera como agregado a la escritura, vuelve como eco o recuerdo, sin fuente, sin origen, sin fijeza, incluso mediada por otra. En la página en la que aparece impreso el poema titulado "la noche", junto al primer verso ("amparo desamparada"), Barrenechea escribe: "Susana le dijo a Renata que "amparo" es verbo: yo amparo" (31).Tal vez el movimiento último de la crítica no sea develar un sentido que surge de comparar versiones, sino poner a circular la palabra, hacer de ese sujeto que la pronunció, no tanto un tema en cuestión como un tema de conversación. Ana María 
recuerda que Susana le dijo o recuerda que Renata le dijo que Susana dijo. Entre el recuerdo y el decir, la poeta se trae a la presencia, su palabra queda reverberando, distinta de sí misma, girando y enlazando a otras, incluso más allá de su presencia y su decir. Impresa, rescatada en borradores, recordada de manera directa o mediada por la traductora, Ana María Barrenechea coloca la voz de Susana Thénon en el centro de una rueda de prácticas, lenguajes y recuerdos. Allí, amparada por la poesía, la crítica acorta las distancias entre un poema y otro, entre una lengua y otra, entre la práctica poética y el misterio del sentido.

\section{La imagen interrumpida}

En una conferencia de 1936, en la Université des Annales, Paul Valéry propone que la danza es "una poesía general de la acción de los seres vivos"; ella "aísla y desarrolla los caracteres esenciales de esa acción, la separa, la despliega" (Valéry 187). Esa capacidad de descomponer el movimiento en unidades menores, de construir a partir de él un lenguaje propio, arrima la danza al lenguaje en general y al discurso poético en particular. Del mismo modo, ese llevar al extremo todas las posibilidades del lenguaje que orquesta el Yo poético acerca la poesía a la danza y permite pensar la práctica poética como una coreografía verbal; Valéry lo resume en un símil que homologa figuras retóricas y destrezas físicas : "la metáfora como una suerte de pirueta de la idea" (188). Paso de danza o zigzag como el que opera, sobre el sentido, el encadenamiento de versos como, por ejemplo, los del poema 29 :

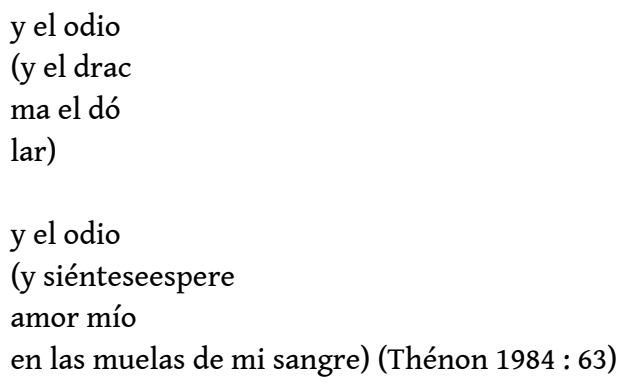

Sin embargo, en los agradecimientos de su libro distancias, lo que Thénon dice recibir de la danza es más específico: Iris Scaccheri, afirma Thénon, le permitió "completar la obra". Esa completitud está ligada al efecto de autonomía que produce una coreógrafa cuando aísla el balanceo de un pie y lo combina con el leve arquearse de una espalda, orquestando una serie completa y cerrada sobre sí misma. Efectivamente, la danza autonomiza el movimiento. Hace de las percepciones y los actos sin consecuencia física vital, su material por excelencia y compone sus coreografías con movimientos corporales sin función en la vida cotidiana. Al dotarlos de utilidad y destino dentro de una secuencia, la danza participa de aquello que, según Paul Valéry, caracteriza al arte en general y que consiste no sólo en hacer de lo inútil algo útil, sino incluso en hacer de lo inútil algo, dentro de su propia esfera de existencia, necesario. La danza le otorga a la poesía una certeza acerca del modo en que la palabra poética vive su existencia, con independencia o al menos a cierta distancia del lenguaje cotidiano -, adquiere espesor de objeto y se articula con otras palabras del poema. La danza implica una serie de acciones que se ejecutan en movimientos sucesivos y tiempos conmensurables, es decir, siguiendo un ritmo. Comparte aquí ese principio constructivo que, según el formalismo ruso, define al lenguaje poético. Autonomía y ritmo, como características en común, cierre y 
completitud como propiedades a imitar o a recibir : regalos desde la danza hacia la poesía, desde Scaccheri a Thénon.

Este vínculo con la danza está planteado incluso antes de los agradecimientos, ya en la tapa de distancias. El libro tiene una cubierta negra, con el nombre de la autora, el título y el nombre del editor ubicados en un espacio pequeño contra el borde superior izquierdo ; el resto es espacio vacío y negro sobre el cual hay una fotografía en blanco y negro de Iris Scaccheri tomada por Susana Thénon. Allí, la bailarina está de espaldas, con los brazos extendidos hacia atrás para darse envión y subir una escalera; allí ha puesto un pie, extendiendo el otro, el rezagado, el que quedó en el suelo. La escalera de la imagen, agudizada por el diseño de la tapa, tematiza el título del libro : escaleras y puentes son elementos que de manera emblemática, acortan las distancias y también las subrayan.

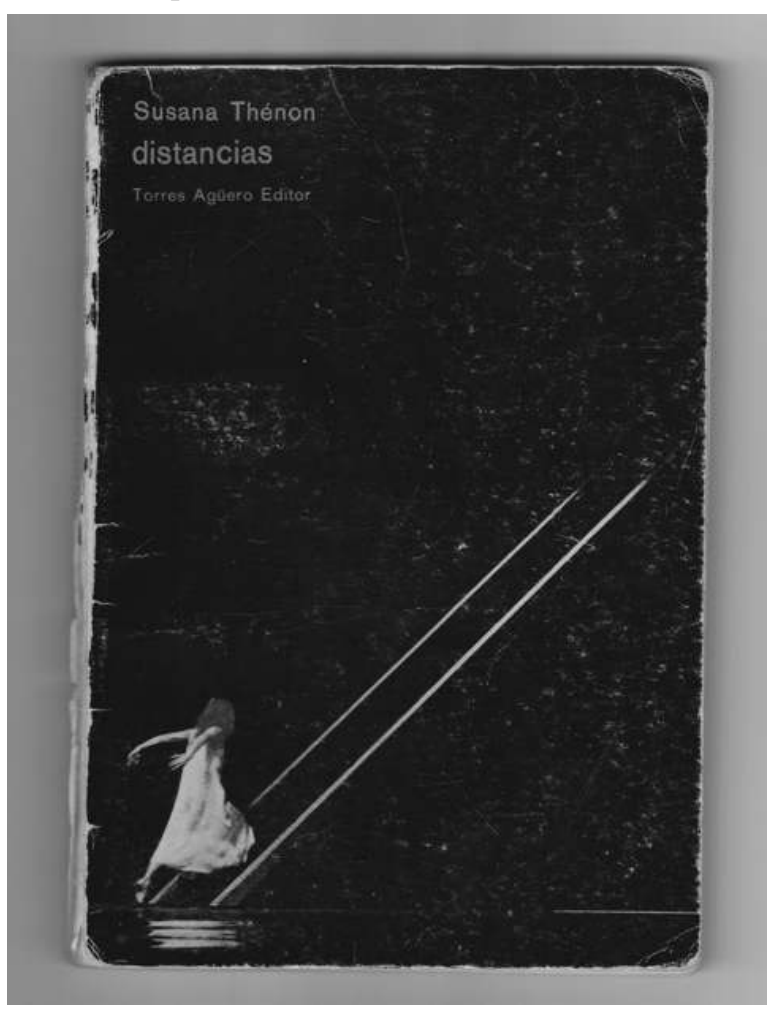

Figura 2: Tapa de distancias

En el diseño de la cubierta, la foto no exhibe sus límites, sino que se confunde con la totalidad de la página. Como si fuera la oscuridad de lo real -esa noche a la que Thénon se refiere en otros poemas -, ese vacío convoca a una retórica de la caminata, el vagabundeo o incluso la danza. Así lo propone el poema 2 :

de cara a la pared

dibujan los ojos dan movimiento

amor y el salto al otro lado

es otro hueco y toda la presencia

otra pared límite blando familiar

la mirada una casa para siempre

solas mesas tendidas

el mundo un paso y otro paso otro paso (10)

El mundo es ese lugar que se toma como familiar -hay cierta domesticidad en esas casas, esas paredes y esas mesas - ; es también un lugar que se recorre con múltiples pasos o 
saltos, de un lado al otro, con el movimiento de la rueda, de la danza, de la escritura. 0 , con esa particular retórica de la mirada que Thénon desarrolló como fotógrafa. Efectivamente, durante los años setenta dejó de escribir para abocarse a la fotografía. Y de hecho, si bien la imagen de la tapa de distancias no es una de las incluidas en el portafolio, parece formar parte de la misma serie de fotografías que Thénon tomó de la bailarina y coreógrafa y publicó luego, en 1988, con el título Acerca de Iris Scaccheri. Esta es una publicación de autor, es decir, producida en una imprenta sin mediación editorial y pagada por la autora y algunas amigas, entre las que estaría Barrenechea. No se trata exactamente de un libro, sino de una carpeta/sobre de $40 \mathrm{~cm}$. x $30 \mathrm{~cm}$. que contiene 36 páginas sueltas y sin numerar. ${ }^{7}$

El objeto mismo, con su formato, su gran tamaño, su papel de alto gramaje y su limitadísimo número de 200 ejemplares, se asemeja más a un portafolio de imágenes sacadas del laboratorio por la artista, que a un libro. Sin embargo, las páginas sueltas siguen los protocolos librescos : la primera página funciona como portada y reproduce la cubierta del sobre; la segunda es una contraportada, con el título en el recto y las indicaciones de imprenta y copyright en el reverso ; la tercera, una declaración/poema de Thénon. Luego de una página en blanco aparecen las 30 imágenes. Son fotos en blanco y negro, impresas hasta el filo de la página, sin marco y con mucho grano ; cada una de ellas está numerada en el anverso y allí se detalla el nombre de la coreografía y el lugar en el que se desarrolló.

21 En su repetición de movimientos puntuados por un tiempo constante, la danza traza sus vínculos con la poesía a través del ritmo. En su particular modo de descomponer el movimiento, de desmenuzar cada uno de los instantes que integran, por ejemplo, el arco que traza un brazo al elevarse, la danza se hermana definitivamente a la imagen fotográfica. Teóricos de la imagen como Roland Barthes y André Bazin han señalado el vínculo entre fotografía, memoria y muerte porque, en una de sus dimensiones, lo fotográfico embalsama el tiempo, eterniza aquello que está destinado a perecer. Pero la fotografía también entabla otra relación con lo temporal, más minuciosa y precisa. A ella se refiere Walter Benjamin cuando afirma que sabemos algo sobre el andar de las personas pero casi nada sobre "esa fracción de segundo en que comienzan a alargar el paso" (Benjamin 48). La mirada captura un movimiento y la cámara es capaz de descomponerlo y así apresar aquello que escapa a la percepción cotidiana. Es en este sentido que Benjamin afirma también que "la naturaleza que habla a la cámara no es la misma que la que habla al ojo" (ídem) : el ojo fotográfico puede captar ese "tramado inconsciente" que subyace al mundo de la conciencia asociado a la mirada.

La fotografía desajusta el instante del flujo de movimiento y aquello que pasaría desapercibido se detiene artificialmente, fotográficamente, para ser contemplado. Sobre esta característica propia de la técnica, el fotógrafo francés Henri Cartier-Bresson construyó su poética visual organizada alrededor de la idea de que una buena imagen debía captar la esencia de un proceso en desarrollo. Cada una de las fotografías de Thénon sobre Scaccheri parece tomada a partir de esta noción del "instant décisif".Me detendré sólo en dos ejemplos.

Una es la imagen correspondiente a "La muñeca", presentada en Frankfurt, Alemania, que cierra el portafolio y también lo abre porque aparece en la portada de la edición. A la derecha, hay una silla cubierta con una tela; ocupando los tres cuartos izquierdos del campo visual, la bailarina está sentada, con las piernas firmes, extendidas y casi a noventa grados del cuerpo pero suspendida en el aire. 


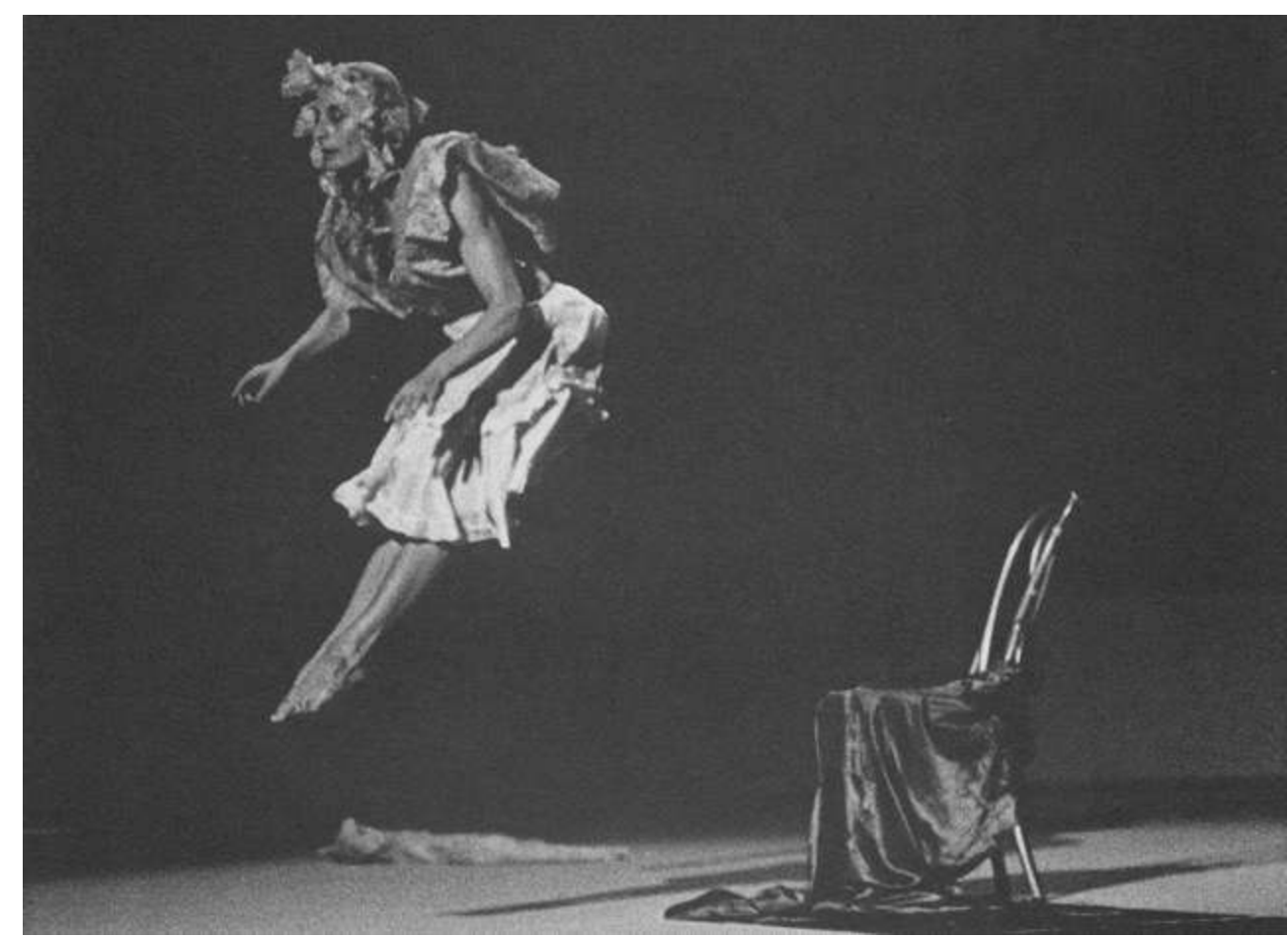

Figura 3: Fotografía de Susana Thénon incluida en Acerca de Iris Scaccheri. Imagen 30 : La muñeca. Schauspiel, Frankfurt, Alemania

El movimiento de Scaccheri es extraordinario en el sentido de irrealizable; la foto de Thénon aísla el instante más alto del salto, y ofrece una imagen en la que no es posible advertir rastros del envión que dio origen al movimiento. Scaccheri queda suspendida en el espacio de la página, como una de esas palabras que Thénon alejaba del resto del verso. La representación visual nos invita a leer el espacio, ya no blanco sino negro, a asombrarnos con la proeza y a veces, a buscar aquellos hilos delgados y casi invisibles que mantienen a la mujer en el aire, como una muñeca de tela y madera. La fotografía de "Carmina Burana", en cambio, parece captar el punto culminante de un salto pero aquí, cada punto de la imagen guarda algo del movimiento que gestó el instante. 


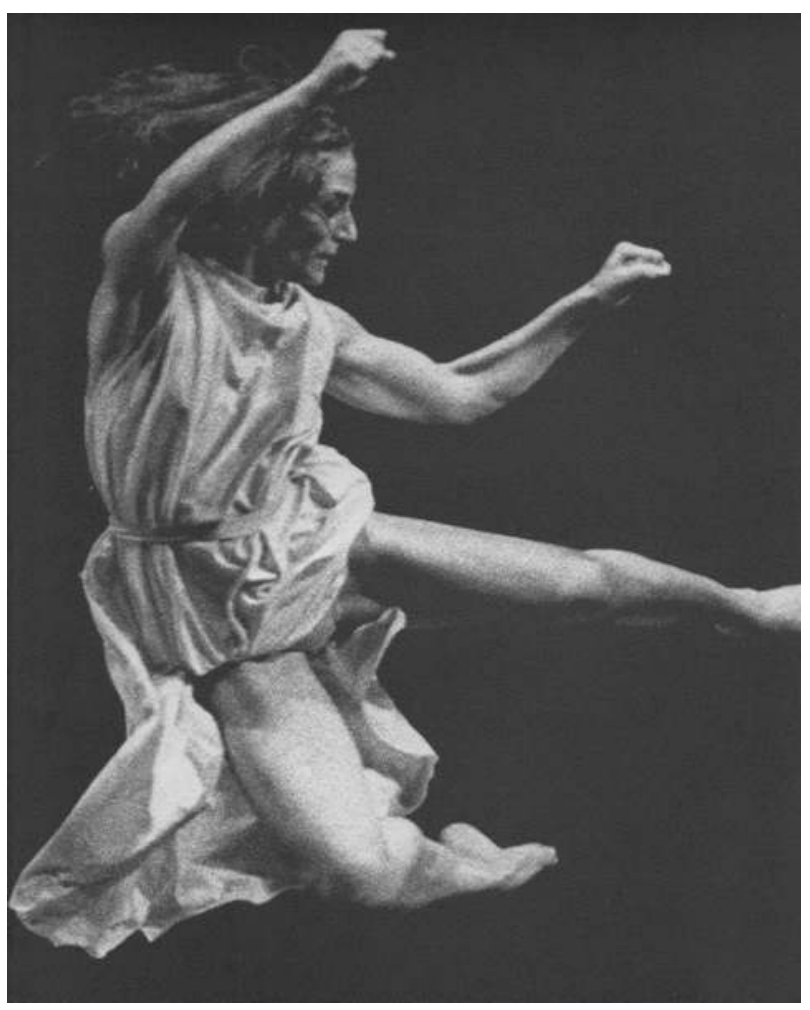

Figura 4: Fotografía de Susana Thénon incluida en Acerca de Iris Scaccheri. Imagen 6 : Carmina Burana. Beethoven Hall, Bonn, Alemania

Cada músculo que se tensa para subrayar una corporalidad vectorial, hecha de líneas rectas, ángulos y fuerzas, cada pliegue de la ropa que se agita con el impulso, cada cabello que se sacude compone la imagen de una estela. Se trata de un fragmento de tiempo congelado, de un cuerpo suspendido por la magia de la danza moderna y la imagen fotográfica. A la vez, la imagen es la representación visual de los efectos de una trayectoria. A partir de ambas imágenes es posible pensar que vale para la fotografía lo que Valéry afirma para la danza : abocarse a "la creación de una clase de tiempo, o de un tiempo de una clase completamente distinta y singular" (Valéry 79). Un tiempo detenido o condensado en imágenes que no se organizan alrededor de la contemplación de la fijeza sino de la escenificación de fragmentos o implosiones de movimiento.

En el segundo poema de distancias citado con anterioridad hay una mirada enamorada del movimiento o que da movimiento ; allí "dibujan los ojos" en una frase que podría ser una bella definición de lo fotográfico. Como poeta Thénon pone a andar una rueda de palabras, como fotógrafa también la hace girar pero lo suyo es un modo velado de la acción. Porque la fotografía es una contemplación fascinada que declara la extranjería de la experiencia ; fotografiar es siempre mirar y quedar, no participar de lo que se mira. "La persona que interviene no puede registrar ; la persona que registra no puede intervenir" (Sontag 22). La bailarina es entonces, la soberana del movimiento y la temporalidad. Su gran otra, su doble, su cómplice, su espía es la fotógrafa. Se trata de otro modo de inscribirse en la rueda de los lenguajes y las prácticas, ahora ya no para ser origen del tejido de palabras, comentarios, recuerdos verbales y borradores, sino para ser la que dibuja con los ojos, la que sabe leer la textura del movimiento, como otras saben leer los movimientos de su lengua poética. Ese ver a la otra, ese verse en la otra, ese verso que habla de ser otra (no sólo "soy dos / una igual una / sin siempre" sino toda la poética de 
Thénon) enlazan una poética del espacio y del movimiento, de las resonancias y los ecos, una rueda en la que circulan otros lenguajes, otras cartas, otras conversaciones, otros lugares, otras mujeres.

\section{Imágenes}

Fig. 1 Página de distancias con anotaciones de Ana María Barrenechea

Fig. 2 Tapa de distancias

Fig. 3 Fotografía de Susana Thénon incluida en Acerca de Iris Scaccheri. Imagen 30 : La muñeca. Schauspiel, Frankfurt, Alemania

Fig. 4 Fotografía de Susana Thénon incluida en Acerca de Iris Scaccheri. Imagen 6 : Carmina Burana. Beethoven Hall, Bonn, Alemania

\section{BIBLIOGRAFÍA}

Barrenechea, Ana María. “Epílogo”. En : Thénon 1984, pp. 85-9.

Barrenechea, Ana María. “Introducción”. Filología XXVII, 1-2, 1994록-4).

Barrenechea, Ana María. "La documentación marginal para distancias de Susana Thénon".

Filología XXVII, 1-2, 1994b (75-90).

Benjamin, Walter. "La obra de arte en la época de su reproductibilidad técnica", Discursos interrumpidos I. Traducción de Jesús Aguirre. Buenos Aires : Taurus, 1989, pp. 15-57.

Grésillon, Almuth. "Qué es la crítica genética”. Filología [Buenos Aires], XXVII, 1-2, 1994 (25-52).

Sontag, Susan. Sobre la fotografía. Traducción de Carlos Gardiní. Barcelona : Edhasa, 1981.

Thénon, Susana. distancias. Buenos Aires : Torres Agüero Editor, 1984.

Thénon, Susana . Acerca de Iris Scaccheri. Buenos Aires : Imprenta Anzilotti, 1988.

Valéry, Paul. “Filosofía de la danza”. En : Teoría poética y estética. Traducción de Carmen Santos. Madrid : Visor, 1990, pp. 173-189. [Recogido en el tomo K de Euvres, Conférences, 1939].

\section{NOTAS}

1. Algunos de esos otros ensayos son: "El texto poético como parodia del discurso crítico : Los últimos poemas de Susana Thénon" (Dispositio XI, 30-32, 1987, pp. 255-72) ; "Ova completa : El apocalipsis según Susana Thénon" (en: Homenaje a Alfredo A. Rogiano en este aire de América, preparado por K. McDuffie y R. Minc, vol.1, 1990, pp. 387-393); "Metamorfosis de espacios, acontecimientos y sujetos textuales en un poema de Susana Thénon" (en : El puente de las palabras. Homenaje a David Lagmanovich, Inés Azar (ed.), Washington : Interamer, 1994) ; "La documentación marginal para distancias de Susana Thénon" (Filología XXVII, 1-2, 1994, pp. 75-90) ; "La genética textual: el proceso dudoso o atípico de una "distancia" de Susana Thénon" (en : Actas del XII Congreso de la Asociación Internacional de Hispanistas, Trevor J. Dadson (ed.), vol. IV, Birmingham : 
University of Birmingham, 1995, pp. 70-80) ; “La poesía de Susana Thénon y su subversión del canon" (en : Atípicos en la Literatura Latinoamericana, Noé Jitrik (comp.), Buenos Aires : Universidad de Buenos Aires, 1997, pp. 207-220) ; y "Susana Thénon destruye y reconstruye su espacio y su cuerpo poético" (Acta Poética 1998) y "Génesis de tres distancias de Susana Thénon" (en : Silva : studia philologica in honorem Isaías Lerner, Isabel Lozano Renieblas y Juan Carlos Mercado (coord.), Madrid : Castalia, 2001, pp. 73-86).

2. El ejemplar de distancias que menciono aquí me fue obsequiado por Ana María Barrenechea en el año 1997 ó 1998. Cada vez que transcribo una de esas anotaciones escritas en lápiz indico la página sobre la cual se hizo. El nombre de autor para la cita es Thénon porque el libro impreso es de su autoría y no hay copyright para la palabra manuscrita.

3. La crítica genética surge en la década del 70 en Francia vinculada al Institut de Textes et Manuscrits Modernes (dependiente del CNRS) y a nombres como Louis Aragon, Louis Hay, Almuth Grésillon y Jean-Louis Lebrave, entro otros, así como a zonas de la producción crítica de Gérard Genette y Jean Starobinski. En la introducción al número de la revista Filología dedicado a la Crítica Genética - a cargo de Élida Lois -, su directora, Ana María Barrenechea, inscribe en esa tradición el trabajo de algunos miembros del Instituto de Filología y Literaturas Hispánicas de la Universidad de Buenos. La línea va desde Amado Alonso y su análisis de las variantes del Fausto de Estanislao del Campo en los años 40, hasta su propio abordaje de los manuscritos de Rayuela de Cortázar, pasando por Raimundo Lida y Emma Speratti Piñero (Barrenechea 1994 a). Una generación de especialistas vinculados más directamente con las reflexiones francesas sobre genética textual constituye un equipo que se define a partir de esta línea crítica y que participa en ciertas ediciones de la Colección Archivos: entre ellos está la misma Élida Lois y otros investigadores como Ana M. Camblong y María Inés Palleiro. Uno de los artículos de ese mismo número sintetiza qué es la genética textual. "Su objeto : los manuscritos literarios, en la medida en que conservan las huellas de una dinámica, la del texto en movimiento. Su método : la puesta al desnudo del cuerpo y del curso de la escritura, que surge a partir de la construcción de una serie de hipótesis acerca de las operaciones escriturarias. Su mira : la literatura como un hacer, como actividad con movimiento" (Grésillon 25).

4. En el artículo publicado en Filología, hay una lista mucho más extensa y sistemática de esos "pre-textos" o al menos, elaborada de manera más precisa y definitiva (véase Barrenechea 1994 b: 75-76).

5. Invitada a "Libro marcado" - un evento organizado por Cecilia Szperling en el que un autor o crítico comenta sobre los subrayados y anotaciones que dejó en los libros que leyó -, María Moreno se refirió al "respeto ridículo" que promueve el subrayado en lápiz, un respeto que ella reconoce practicar - como la amplia mayoría de los lectores-, porque deja marcas que de todas maneras nunca van a ser borradas. Aunque es cierto que este respeto es un poco falso en lo que respecta a la posibilidad de ser borrado, sí hay un respeto firme y verdadero en lo que hace a la relación con el texto que comenta. La inscripción en lápiz comparte la página con la marca impresa y pese a que el espacio es común, en su materialidad misma parece ubicarse y reconocer su carácter secundario y, aunque no sea borrada nunca, su ser potencialmente provisorio.

6. Las anotaciones mencionan varias veces una carta de Thénon enviada a Barrenechea, y otra enviada a Treitel en 1993, además de hojas sueltas con distintos poemas. Además, hay varias menciones, -por ejemplo, junto al poema 35-a una lista que también habría recibido la traductora. Junto al poema 35, Barrenechea consigna una lista de versiones, la número 3) aparece indicada como Renata 1993 y se trata, seguramente, de la carta que recibió en ese año ; la 4) es : "Renata lista -1-". En el artículo sobre la documentación marginal, publicado en Filología, Barrenechea consigna ambas correspondencias, de manera englobadora y genérica. Bajo el subtítulo "Los papeles de la autora y la documentación marginal" se menciona " 1 " Correspondencia entre S.T. y yo" y " $3^{\circ}$ copias fotoestáticas de la correspondencia entre S.T. y su traductora al inglés, Renata Treitel” (Barrenechea 1994 b : 75). Aquí, además de ofrecer una 
pequeña biografía de Renata Treitel (nació en Suiza, se educó en Italia, Argentina y Estados Unidos, obtuvo un máster en inglés y español, es poeta, traductora y crítica, a ella se le debe la edición bilingüe de distancias, aprobada por Thénon), Barrenechea señala también que Thénon le regaló "copias de su larga correspondencia y su conversación con R.T. para esclarecer detalles de su compresión muy puntuales o para orientarla en el sentido global de su producción" (76).

7. Varias de estas imágenes se reproducen en Brindis a la danza (Buenos Aires : Leviatán, 2011), un libro editado por Aurelia Chilemi que reúne notas, apuntes y reflexiones de Scaccheri sobre la danza, una cronología sobre su vida personal y profesional como bailarina y coreógrafa y una serie de fotos, todas tomadas por Thénon.

\section{RESÚMENES}

Este ensayo presenta y pone en contacto una serie de materiales : el libro distancias, de Susana Thénon, las anotaciones que Ana María Barrenechea inscribe en un ejemplar de este libro, y el portafolio Acerca de Iris Scaccheri con fotografías tomadas por Thénon de distintas presentaciones de la bailarina y coreógrafa. A partir de ellos, aquí se intenta una reflexión sobre las zonas de contacto e intercambio entre el universo poético, las operaciones de la crítica y la traducción, la temporalidad de la danza y la imagen fotográfica. No se los aborda sólo en tanto lenguajes productores de objetos específicos y autónomos sino fundamentalmente, en tanto prácticas que traman vínculos y formas de asociación entre sujetos históricos específicos : Susana Thénon, Ana María Barrenechea, Renata Treitel, Iris Scaccheri.

Cet article présente et met en relation un ensemble de matériaux : le livre de poèmes distancias, de Susana Thénon, les annotations qu'Ana María Barrenechea fit sur un exemplaire de ce livre, et le dossier Acerca de Iris Scaccheri qui contient des photos prises par Thénon des performances de Scaccheri. A partir de ces matériaux l'essai explore les zones de contact et d'échange entre l'univers de la poésie, les opérations de la critique et de la traduction, la temporalité de la danse et l'image photographique. Ces langages ne sont pas abordés seulement en tant que producteurs d'objets spécifiques et autonomes, mais plutôt comme des pratiques qui tissent des liens et des associations entre des sujets historiques spécifiques: Susana Thénon, Ana María Barrenechea, Renata Treitel, Iris Scaccheri.

This paper presents and connects a range of materials: distancias, Susana Thénon's book of poems, Ana María Barrenechea's annotations made on a copy of this book, and the portfolio Sobre Iris Scaccheri with photographs taken by Thénon during Scaccheri's performances. Taking them as a point of departure, this essay explores contacts and exchanges between the world of poetry, the operations of criticism and translation, the timing of modern dance and photographic image. They are addressed not only as languages producing specific and autonomous objects but fundamentally, as practices that weave links and associations between specific and historical individuals : Susana Thénon, Ana María Barrenechea, Renata Treitel, Iris Scaccheri. 
ÍNDICE

Mots-clés: Poésie, photographie, danse, critique génétique, Thénon

Keywords: Poetry, photography, dance, genetic criticism

Palabras claves: Poesía, fotografía, danza, crítica genética

\section{AUTOR}

PAOLA CORTÉS ROCCA

CONICET

pcortes@sfsu.edu 